\title{
Achenbach Syndrome in a 19-Year-Old Girl: Case Report and Review of Literature
}

\author{
Daniela de Oliveira Werneck Rodrigues ${ }^{1, *}$, Nathalia Noyma Sampaio Magalhães ${ }^{2}$, Olivia Franco dos Santos ${ }^{3}$, Renato Lourenço \\ de Medeiros ${ }^{2}$, and Luisa de Oliveira Werneck Rodrigues ${ }^{4}$
}

${ }^{1}$ Fundação Hemominas, Brazil

${ }^{2}$ Faculdade de Ciências Médicas e da Saúde de Juiz de Fora FCMS/JF (Suprema), Minas Gerais, Brazil

${ }^{3}$ Universidade Federal de Juiz de Fora (UFJF), Minas Gerais, Brazil

${ }^{4}$ Carleton University Science Department, Ottawa, Canada

*Corresponding author: Daniela de Oliveira Werneck Rodrigues, Fundação Hemominas Minas Gerais Rua Barão de Cataguases, Juiz de Fora-MG, Brazil, Tel: +55 32 999796484; +55 32 32573126; Fax: 323257 3100; E-mail: danielawerneckhemato@hotmail.com; daniela. werneck@hemominas.mg.gov.br

Received: 20 Jun, 2020 | Accepted: 04 Aug, 2020 | Published: 11 Aug, 2020

Citation: Rodrigues DOW, Magalhães NNS, Santos OF, Medeiros RL, Rodrigues LOW (2020) Achenbach Syndrome in a 19-Year-Old Girl: Case Report and Review of Literature. J Blood Disord Med 4(1): dx.doi.org/10.16966/2471-5026.123

Copyright: (C) 2020 Rodrigues DOW, et al. This is an open-access article distributed under the terms of the Creative Commons Attribution License, which permits unrestricted use, distribution, and reproduction in any medium, provided the original author and source are credited.

\begin{abstract}
Background: Paroxysmal finger hematoma also known as "Achenbach syndrome" (AS), first described by Walter Achenbach in 1958, is a benign condition resulting in the sudden appearance of paroxysmal bruising on one or more fingers, mostly into the volar surface, either spontaneously or after minimal trauma. In some cases, the bruising may be accompanied by pain and swelling. The authors report a case of a 19-year-old girl with episodes of recurrent hematomas with spontaneous improvement in the fingers and toes and with normal laboratory and radiological exams. The diagnosis of AS was made after a deep evaluation by the Hematology Service. AS is a rare pathology, with few reports in the literature and that no specific treatment is required, whose pathophysiology has not yet been established. The importance of this AS case report is the need to keep this unusual diagnosis in mind in the face of a patient with recurrent hematomas with spontaneous resolution in the fingers and toes.
\end{abstract}

Keywords: Cyanosis; Differential diagnosis; Haematoma; Blood coagulation disorder

\section{Introduction}

Achenbach syndrome (AS) or paroxysmal hematoma of the digits is a rare, benign and self-limited condition characterized by a sudden, spontaneous, intermittent and recurrent appearance of paroxysmal hemorrhagic lesion in the subcutaneous of the fingers, especially in the second and third fingers and palmar region. It has a higher incidence in middle-aged women [1-4] and it may be associated with pain, edema and paresthesia [5]. The pathophysiology has not yet been established. Although the cause is unknown, the possible association with minor traumas that could lead to capillary microhemorrhage in $33 \%$ of cases is discussed [6].

Most patients seek medical attention due to pain and sudden bruising, the main diagnoses to be considered are: Raynaud's phenomenon, acute limb ischemia, Buerger's disease, acrocyanosis, vasculitis, Gardner-Diamond syndrome and dermatitis artefact $[7,8]$. The figure 1 shows the algorithm proposed by Brown, Zirwas and English III, 2010 for the investigation of purple digit [9].

The evaluation of vascular flows performed through angiography, capillaroscopy and venous and arterial doppler are normal in AS and do not contribute to the diagnosis considering that there is no vascular injury. Skin biopsies, when performed, may have a normal result or may not provide conclusive information [10]. In the investigation of purple fingers, laboratory tests are normal, with no evidence of hematological and/or rheumatological diseases [1-4].

The aim of this case report on AS is to draw attention to a disease that, although rare, should be considered in case of blue digits.

\section{Case Report}

A 19-year-old woman (O+ blood type) presented to the emergency department with acute painful and bruised index digit of the left hand (Figure 2A). She was first seen by a clinician and later referred to the Hematology Service due to the recurrence of the condition. The patient reported three recurrent appearance of "blue fingers" (Figures $2 \mathrm{~B}$ and $2 \mathrm{C}$ ) for three months and the situation usually improved spontaneously. The body parts involved in these episodes were: index finger of the left hand, dorsal area of the right and the left feet and both surfaces of the right hand on the ring finger. The patient was in a moment of extreme anxiety due to the proximity of the university admission exams, with pessimistic, depressive thoughts and low self-esteem. 


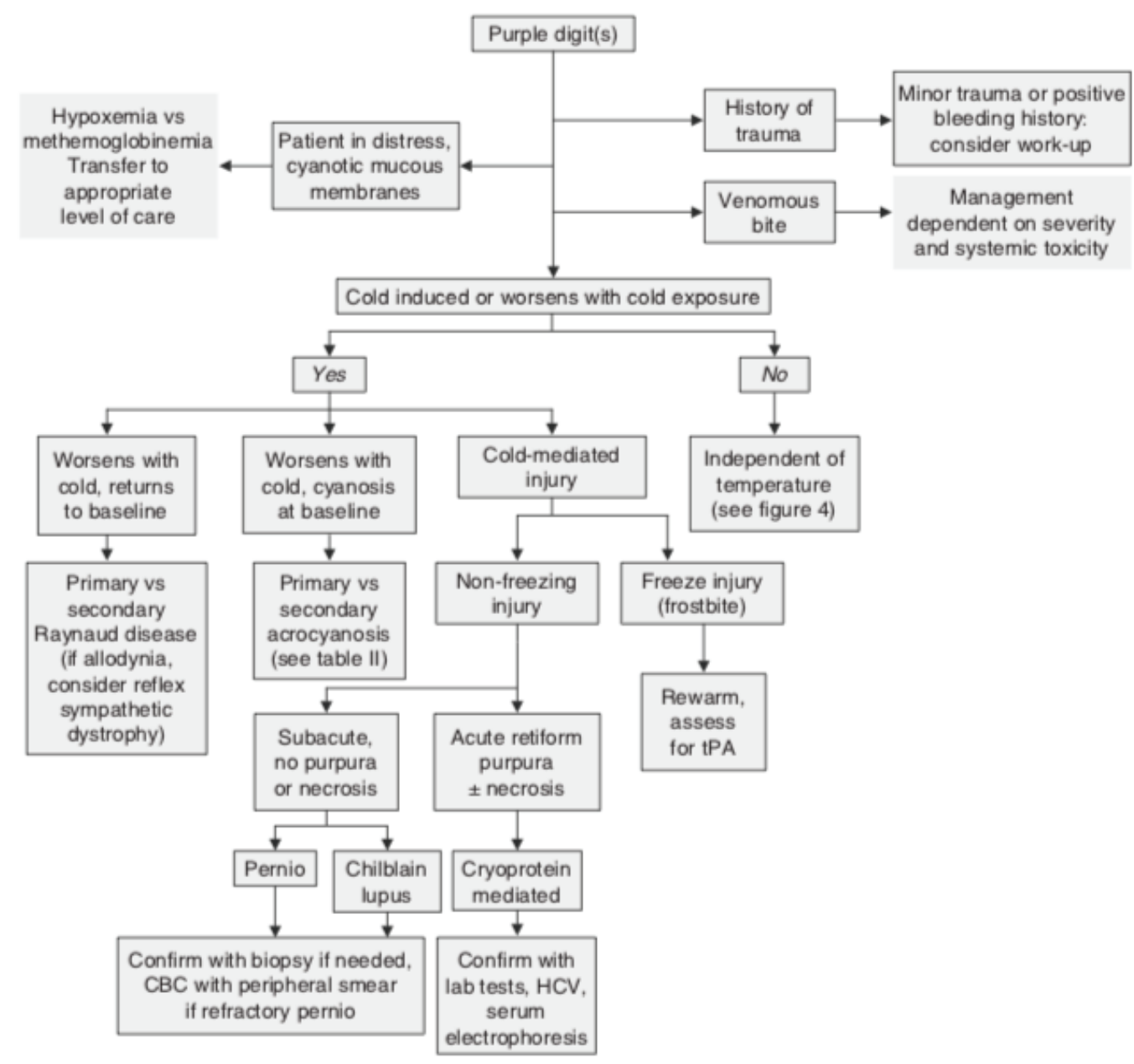

Figure 1: Algorithmic Approach to diagnosis the Purple Digit (CBC: Complete Blood Count; Hcv: Hepatitis C Virus; tPA: tissue Plasminogen Activator).

Source: Brown, Zirwas and English III, 2010 (image used with permission of the authors)

The patient did not referred epistaxis, gingivorrhagia nor hematuria episodes and no recent trauma was reported. As for her menstrual cycle, there were no changes. The patient consumed a few amounts of alcohol, was a non-smoker, was sedentary and had tattoos, which did not involve any complications such as bleeding. She had a healthy brother and there was no history of hemorrhagic or thrombotic diseases in her family. Besides that, she was very anxious, as she was about to take her admission exams.

On physical examination, the patient had acne vulgaris on her face. There were no chest nor abdominal abnormalities and the cardiovascular evaluation was normal. Both right and left brachial, radial and ulnar arteries were well palpable. The oxygen saturation was $98 \%$.

The index digit of the left hand was swollen to the level of the metacarpophalangeal joint with bruising over both surfaces of the hand, more intense in the palmar area (Figure 2A).

Considering clinical history data and physical examination, hematological, rheumatological and thyroid exams were requested. The results are shown below (Table 1). In addition to laboratory tests, a venous and arterial vascular study was performed using the doppler ultrasound technique, which did not show any changes.

Considering that the initial screening exams were normal, the Hematologist requested for a deeper evaluation of possible rare coagulation disorders, which were described in the table 2 .

Considering clinical history, laboratory exams and normal imaging exams, the diagnosis of AS was made.

\section{Discussion}

AS is a rare clinical entity that courses with "blue fingers" on one or more digits and may be associated with pain, edema and paraesthesia [11]. The aetiology is unknown but it can have a spontaneous onset or appear after a minimal trauma, such as open a jar $[12,13]$. The disease is self-limiting and progresses favourably [6]. There is no therapeutic approach since the condition regresses naturally without the need of drug treatment [14].

It is highly reported in the literature cases in which the symptoms appear on the middle and on the index fingers, as seen in our case $[1,2,4,5,13-21]$. However, it is possible to observe Achenbach's signs 

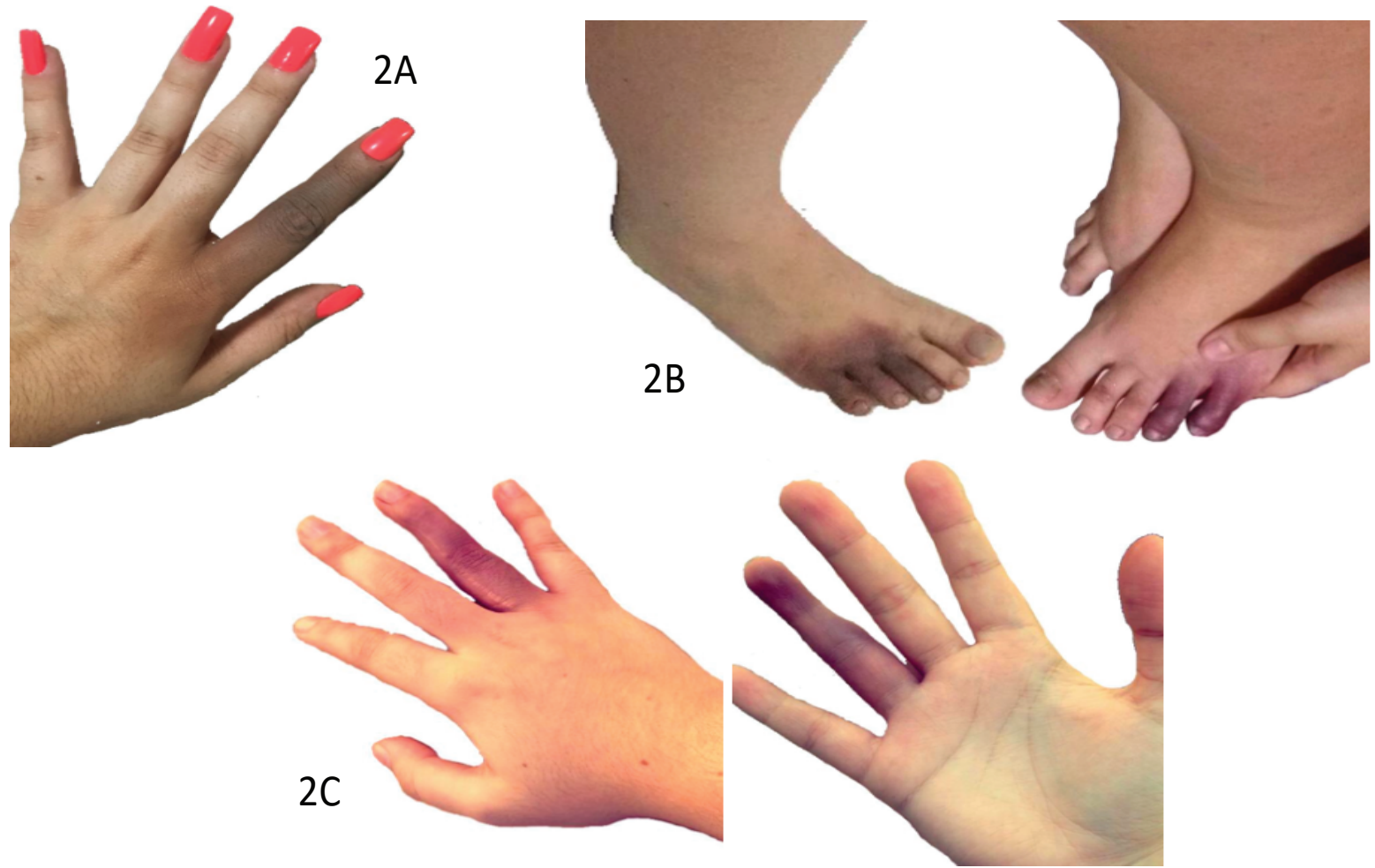

Figure 2: Acrocyanosis lesions on the index finger of the left hand $(A)$, dorsal area of the right and the left feet (B) on both surfaces of the right hand on the ring finger $(C)$.

Source: Photograph taken by the patient.

Table 1: Hematological and, rheumatological exams' results.

\begin{tabular}{|c|c|c|c|c|c|}
\hline Parameter & Results & Parameter & Results & Parameter & Results \\
\hline Hemoglobin & $12 \mathrm{~g} / \mathrm{dL}$ & Direct bilirubin & $0.4 \mathrm{mg} / \mathrm{dL}$ & Crioglobuline & Negative \\
\hline Hematocrit & $37 \%$ & ESR & $2 \mathrm{~mm}$ (first hour) & ANCA P,C & Negative \\
\hline Leucocytes & 7600 cels $/ \mathrm{mm}^{3}$ & B12 & $400 \mathrm{pg} / \mathrm{mL}$ & ANTI RNP & Negative \\
\hline Neutrophil & $41 \%$ & Calcium & $9.8 \mathrm{mg} / \mathrm{dL}$ & ANTI SM & Negative \\
\hline Lymphocyte & $44 \%$ & Antinuclear antiboides & Negative & ANTI SSA (Ro) & Negative \\
\hline Platelets & $189 \times 10^{9} / \mathrm{L}$ & Anti DNA & Negative & ANTI SSB (La) & Negative \\
\hline PA & $86 \%$ & $\mathrm{C} 3$ and $\mathrm{C} 4$ & Normal & Lupus anticoagulant & Negative \\
\hline aPTT & $35 \mathrm{~s}$ & Fibrinogen & $400 \mathrm{mg} / \mathrm{dL}$ & Bleeding time & $1^{\prime}$ \\
\hline LDH & 235 UI/L & $\mathrm{CH} 100$ & Normal & Protein Electrophoresis & Normal \\
\hline Total bilirubins & $0.8 \mathrm{mg} / \mathrm{dL}$ & Crioaglutinine & Negative & Anticardiolipin IgG, IgM & $<9.4 \mathrm{GPL},<9.4 \mathrm{MPL}$ \\
\hline
\end{tabular}

Subtitles: PA: Protrombin Activity; aPTT: activated Partial Thromboplastin Time; LDH: Lactate Dehydrogenase; ESR: Erythrocyte Sedimentation Rate; ANCA C: Cytoplasmic perinuclear active antineutrophil cytoplasmic antibody; ANCA P: Perinuclear Active Antineutrophil Cytoplasmic Antibody; ANTI RNP: Anti-Ribonucleoprotein. 
Table 2: Blood Coagulation Results.

\begin{tabular}{|c|c|c|c|c|c|}
\hline Parameter & Results & Reference rage & Parameter & Results & Reference rage \\
\hline AP & $88 \%$ & $\geq 70 \%$ & Factor $\mathrm{X}$ & $83 \%$ & $60-130 \%$ \\
\hline INR & 1.06 & 1.3 & Factor XI & $111.1 \%$ & $60-140 \%$ \\
\hline aPTT & $30.2(26.8)$ & $24-40$ seconds & Factor XII & $80 \%$ & $60-140 \%$ \\
\hline Factor II & $123.4 \%$ & $60-140 \%$ & Factor XIII & $146.8 \%$ & $60-140 \%$ \\
\hline Factor $\mathrm{V}$ & $127.2 \%$ & $60-140 \%$ & Von Willebrand antigen & $80 \%$ & $50-120 \%$ \\
\hline Factor VII & $96 \%$ & $70-130 \%$ & Co ristocetin factor & $65 \%$ & $50-150 \%$ \\
\hline Factor VIII & $82.9 \%$ & $50-200 \%$ & Inhibitor research & Negative & Negative \\
\hline Factor IX & $127.9 \%$ & $60-140 \%$ & $\begin{array}{c}\text { Platelet aggregation curve (ADP, } \\
\text { Ristocetin, Adrenalin) }\end{array}$ & \multicolumn{2}{|c|}{ Normal } \\
\hline
\end{tabular}

Subtitles: AP: Activated Protrombin; INR: International Normalized Ratio; aPTT: activated partial Thromboplastin time; ADP: Adenosine Diphosphate. Source: The authors.

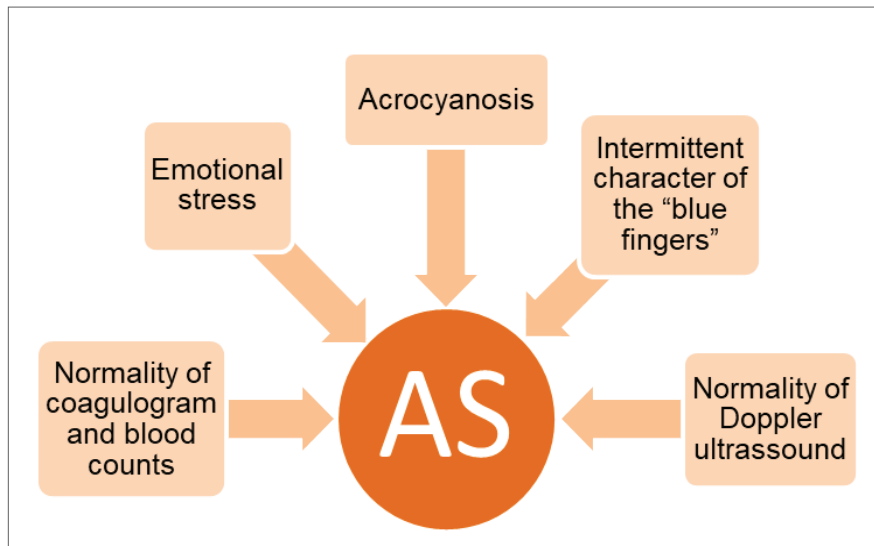

Figure 3: Diagram of diagnostic suspicion.

on other digits, such as the thumb and the ring and middle fingers $[7,8,11,12,18,22,23]$. The acrocyanosis lesions were as well observed on the toes in our patient (Figure 2B) and reported in the literature $[3,12]$.

That's why Pavlovic MD, et al. [24] suggests that "paroxysmal acral haematoma" is a more appropriate name than "paroxysmal finger hematoma." Nevertheless, Achenbach syndrome were also reported on the wrist and in the eyes $[25,26]$.

AS is commonly observed in women between their fifth and sixth decade of life [18]. However, it has already been diagnosed in people under 40 years old and it was our patient's case $[8,12,14,16,18,22]$. Besides that, Ada F, et al. [27], in a retrospective review of 24 patients diagnosed with AS, reported that $83.3 \%$ were female. Still, man can be diagnosed too [5,22]. Takeuchi $\mathrm{H}$, et al. [22] describes a case in which the patient was not only young (20 years old), but also a man.

Yamamoto Y [1] published the case of a healthy 66-year-old woman with sudden-onset pain and bruising in her right middle finger. Similar to our case, she reported that had not had any recent trauma and the episode resolved spontaneously, without the use of medication. Laboratory tests were done revealing normal platelet count and no coagulopathy, as shown in this present case report. A clinical diagnosis of Achenbach's syndrome was made.
Similarly, Frerix M, et al. reported the occurrence of spontaneous sensation of pain and bluish discoloration of the fingers in a 49-yearold woman. The condition also had no association with physical strain or exposure to cold temperatures [15]. This case was one of the few in which capillaroscopy was performed. Multiple and severe hemorrhages were found on the right middle finger, without any other morphological nor blood flow alterations at any other digit. These findings indicate that capillary microhemorrhages may be related to the pathophysiology of AS.

Moreover, Suzuki J, et al. [14] pointed out the case of a previously healthy 30 -year-old Japanese woman presented with a sudden pain and swelling of her left third finger. As the other cases, the patient denied using any medications, any recent trauma, or a history of similar episodes. There was no platelet deficiency or coagulation disorder, conformable our patient. Symptom improvement was observed within three days without treatment or relapse.

AS's diagnosis is essentially based on history and clinical examination and the knowledge of this condition facilitates the diagnosis (Figure 3). Kordzadeh A, et al. [6] proposed an algorithm based on the palpability of the pulses, the patients' age and sex, the colour, the frequency, the anatomic location and other characteristics of the acrocyanosis lesions. It aims to facilitate the differential diagnosis and to distinguish AS from other mild bleeding disorders.

In the evaluation of differential diagnoses, AS is characterized by the absence of any clinical abnormality and complementary exams, below we will discuss the nosological pathologies in the investigation of purple digit.

Similar to acute limb ischemia, the presentation is sudden (24-48 h) and is presented with discoloration, pain, edema and paresthesia. However, in AS, there is a predominance of females and older individuals, in addition to the time resolution being lower, the pulses being palpable and the peripheral temperature being normal [6].

Buerger's disease or Thromboangiitis obliterans also has a similar presentation, although it is more common in men and it is mainly associated with tobacco exposure. It results in ulceration and gangrene of the digits of the hands and feet, symptoms that may improve as soon as the exposure to tobacco stops [10]. 
Another differential diagnosis is Raynaud's Syndrome (RS), which is more common in women as well, but its presentation is more chronic and episodical [6]. RS has an association with seasonal changes, being induced by cold weather (ice water immersion with temperature recovery is sensitive but not specific). Moreover, RS can appear clinically with connective tissue disorders, such as systemic lupus. In addition, the colors are not restricted to bluish; it varies from purple to white [28].

Acrocyanosis should also be considered a differential diagnosis. It is also a rare and benign condition, but, as opposed to AS, it affects both sexes equally and has a median age of 30 years, although it can be seen in children as well. The clinical presentation is symmetrical, and may involve hands, fingers and face. Apparently, it is related to cold weather, outdoor occupation and low body mass index (BMI) [6].

In addition, Gardner-Diamond Syndrome is another condition that may resemble AS [11]. The disease is described as idiopathic and dominant in females, exhibiting discoloration, pain and edema which, however, can affect any part of the body and is associated with personality disorders, nausea, syncope and bleeding. There may also be joint and musculoskeletal manifestations. None of the above was reported by the patient [10].

Finally, dermatitis artefact a has also a similar clinical presentation. It is a psychocutaneous disorder in which the skin lesions are selfinduced, but there was no evidence for this condition in our patient $[8,29]$.

Besides all these syndromes and diseases that have a similar presentation to AS, it is possible to reach the diagnosis trough complementary exams. Blood counts, conventional radiology and coagulation, autoantibody and vascular flow studies show no alteration in AS. The exams requested to the patient were normal: laboratory studies showed no abnormalities in platelet count, coagulation, autoantibody, such as antinuclear antibody and anti-phospholipid antibody. Arterial and venous Doppler Ultrasound of lower members presented without changes [6].

AS can be triggered by stress, when our patient was admitted to the Hematology Service, she was extremely anxious and had a depressive status considering the proximity of pre-admission exams to the university. The intermittent and recurrent character of the "blue fingers", with normal exams, was crucial and decisive for the diagnosis of AS. In our case, there was no abnormal personal or family history, similar to another case presented $[1,11,15,22,25]$.

The patient's last appointment with the Hematologic department was on 2020, at this moment she was informed about the benignity of the syndrome and possible repetition of symptons, then she was referred to a Psychiatric service. She has not presented any symptoms since then. No specific treatment was instituted and there was spontaneous regression of the condition.

\section{Conclusion}

Due to the benign and self-limiting character of the syndrome, no specific treatment has been proposed. Patients should be advised about the possibility of symptom recurrence in order to prevent anxiety, as the manifestations of the syndrome may be alarming. Although benign, AS may have a significant impact on quality of life.

\section{Acknowledgement}

The authors would like to thank the patient who allowed her history to be published.

\section{Conflict of Interest}

The authors declare that there is no conflict of interests regarding the publication of this paper.

\section{References}

1. Yamamoto Y, Yamamoto S (2017) Achenbach's Syndrome. N Engl J Med 37: e53.

2. Sigha B, Josselin L, Gatfosse M, Fardet $L$ (2016) Paroxysmal finger haematoma (Achenbach syndrome). Ann Dermatol Venereol 143: 130-133.

3. Pavlović MD, Loubser MD (2019) Paroxysmal acral haematoma is a more appropriate name for Achenbach syndrome. Clin Exp Dermatol 44: e18-e19.

4. Ahmed Z, Elmallah A, Elnagar M, Dowdall J, Barry M, et al. (2018) Painful Blue Finger-Achenbach's Syndrome: Two Case Reports. EJVES Short Rep 40: 1-2.

5. Notomi K, Harada T (2019) Achenbach syndrome. CMAJ 191: E584.

6. Kordzadeh A, Caine PL, Jonas A, Rhodes KM, Panayiotopolous YP (2016) Is Achenbach's syndrome a surgical emergency? A systematic review. Eur J Trauma Emerg Surg 2: 439-443.

7. Ribeiro F, Aveiro M, Leal M, Valente T, Jesus G (2019) An Acute Blue Finger: A Case of Achenbach's Syndrome. Eur J Case Rep Intern Med 6: 001231.

8. Parslew R, Verbov JL (1995) Achenbach syndrome. Br J Dermatol 132: 319.

9. Brown PJ, Zirwas MJ, English JC $3^{\text {rd }}$ (2010) The purple digit: an algorithmic approach to diagnosis. Am J Clin Dermatol 11: 103-116.

10. Godoy A, Tabares AH (2019) Achenbach syndrome (paroxysmal finger hematoma). Vasc Med 24: 361-366.

11. Kluger N, Serres-Cousiné A, Girard C, Guillot B (2011) Paroxysmal hematomas of the digits (Achenbach's syndrome). Presse Med 40: 326-327.

12. Cohen SN (2018) Personal observations of Achenbach syndrome. Clin Exp Dermatol 43: 933-934.

13. Castillo SA, Dinulos JG, Werchniak AE (2020) Painful ecchymosis of the finger: a case of Achenbach syndrome. Int J Dermatol 59: 862-863.

14. Suzuki J (2019) Achenbach's Syndrome in a 30-year-old Healthy Woman. Intern Med 58: 1807.

15. Frerix M, Richter K, Müller-Ladner U, Hermann W (2015) Achenbach's syndrome (paroxysmal finger hematoma) with capillaroscopic evidence of microhemorrhages. Arthritis Rheumatol 67: 1073.

16. Harper CM, Waters PM (2013) Acute idiopathic blue finger: case report. J Hand Surg Am 38: 1980-1982.

17. Seifman MA, Johnstone BR (2018) The Acutely Blue Finger: Cause for Concern? J Hand Surg Asian Pac 23: 294-296.

18. Robertson A, Liddington MI, Kay SP (2002) Paroxysmal finger haematomas (Achenbach's syndrome) with angiographic abnormalities. J Hand Surg Br 27: 391-393.

19. Picón Jaimes YA, Orozco Chinome JE, Molina-Franky J (2019) Spontaneous digital hematoma, Achenbach Sindrome. Rev Fac Cien Med Univ Nac Cordoba 76: 257-260.

20. Blaison F, Lifermann F, Baudry V (2019) A blue finger. Rev Med Interne 40: 197-198.

21. Yie K (2019) Achenbach Syndrome: A Benign Painful Blue Finger with Tip Sparing. Vasc Specialist Int 35: 251-253. 
22. Takeuchi H, Uchida HA, Okuyama Y, Wada J (2016) Acute idiopathic blue fingers: a young man with Achenbach's syndrome. BMJ Case Rep.

23. Yamada T (2018) Achenbach's syndrome in an elderly woman. J Gen Fam Med 19: 65-66.

24. Pavlović MD, Loubser MD (2019) Paroxysmal acral haematoma is a more appropriate name for Achenbach syndrome. Clin Exp Dermatol 44: e18-e19.

25. Huikeshoven M, de Priester JA, Engel AF (2009) A case of spontaneous wrist haematoma in Achenbach syndrome. J Hand Surg Eur 34: 551-552.
26. Young B, Okera S (2018) Recurrent subconjunctival haemorrhage in Achenbach's syndrome. Clin Exp Ophthalmol 46: 965-966.

27. Ada F, Kasimzade F (2019) Analysis of 24 patients with Achenbach's syndrome. World J Clin Cases 7: 1103-1110.

28. Valdovinos ST, Landry GJ (2014) Raynaud syndrome. Tech Vasc Interv Radiol 17: 241-246.

29. Kumaresan M, Rai R, Raj A (2012) Dermatitis artefacta. Indian Dermatol Online J 3: 141-143. 